EP\&S DIVISION TECHNICAL NOTE

$$
\text { No. } 52
$$

B.B. Culwick

June 26, 1972

\title{
Datacom Interface to Magnet Power Supplies
}

Control and monitoring of devices in experimenters beam 1 ines will be accomplished over a communication link called a DATACOM $1,2,3$. Use of the system for this application requires definition of the device dependent portions of the transmitted and received words. The definitions and their explanation are given below.

\section{Datacom Format}

Transmissions between the central module and the remote receiver consist functionally of 3 fields. (Figure 1) The 8 bit address field is the standard DATACOM address which identifies the remote receiver. The COMMAND/STATUS field defines the commands to a device and the status received from a device. The MAGNITUDE field contains the set point data sent to a device on a SET command and the digitized analog voltage received from the device in any cycle.

\section{Datacom Eunction SET}

The detailed bit assignments for this function are shown in Table 1 and Figure 2.

\section{Datacom Function READ}

Following standard Datacom conventions, the READ function does not affect conditions in the power supply, but returns status and magnitude information to the central module. The bit definitions for READ are given in Figure 3.

\section{Datacom Function READ and SET CHANNEL}

This function is used to both return status and magnitude for a channel and to set a new value into the multiplexer sub-address. The new analog voltage will not be digitized until the next conversion by the ADC. The ADC invalid bit will be set until this conversion is complete. Bit assignments are given in Figure 4.

* Indicates corrections 


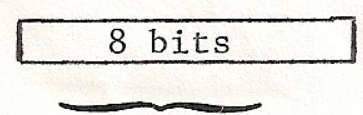

Remote Receiver Address

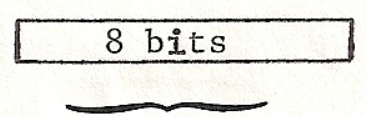

Command Status

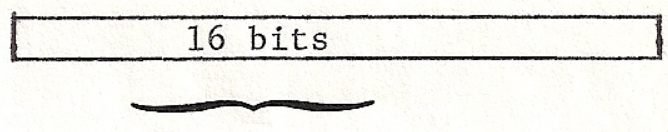

Magnitude

\section{FIGURE 1 Datacom Word Format}

Central to Remote:

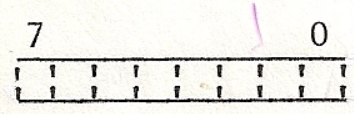

Remote Receiver Address

Remote to Centra1:

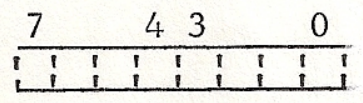

Unused
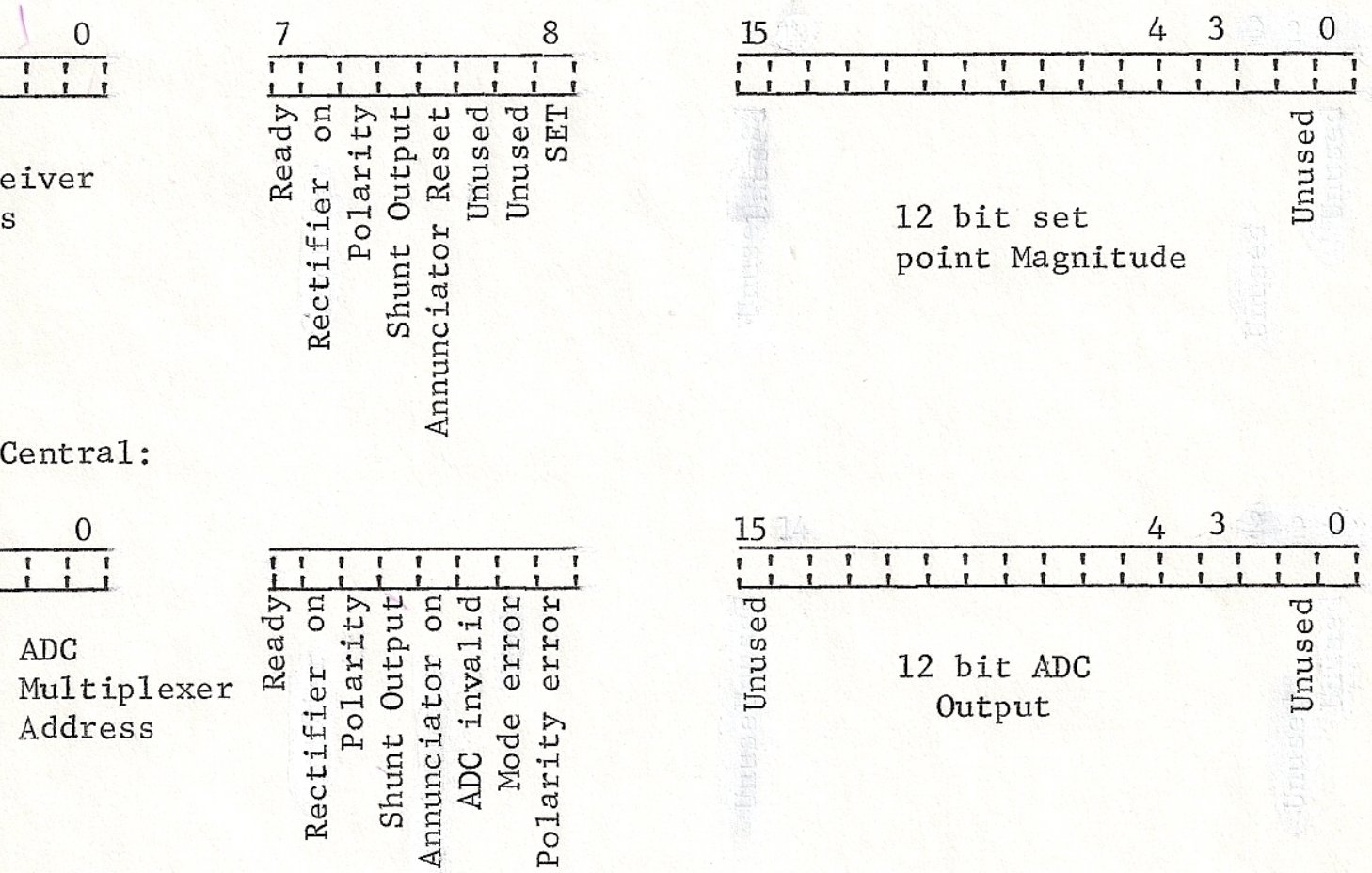

FIGURE 2 Datacom Function SET bit definitions

Central to Remote:

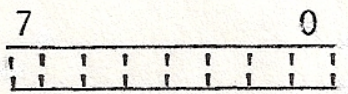

Remote Receiver Address

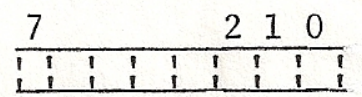

Unused 00

$=$ READ

*

Remote to Centra1: As for SET

FIGURE 3 Datacom Function READ bit Definitions 
Central to Remote:

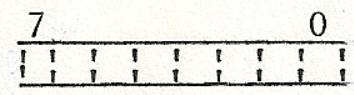

Remote Receiver Address

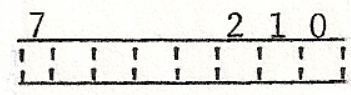

Unused 10 $=$ READ $\&$ SET CHANNEL

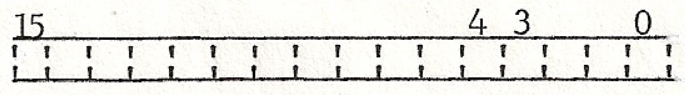

Unused

Sub-Address

Remote to Central : As for SET

FIGURE 4 Datacom Function READ \& SET CHANNEL bit Definitions.

\section{$\underline{\text { References }}$}

1. EP \& S Division Technical Note 49, Single Wire Datacom Link V.J. Kovarik

2. EP \& $S$ Division Technical Note 53 PDP-11 Datacom Interface B.B. Culwick

3. EP \& S Division Technical Note 52 Datacom Serial Transmission System for the PDP-11 B.B. Culwick 


\section{TABLE 1}

Centra1 to Remote:

\begin{tabular}{|c|c|c|c|}
\hline FIELD & BIT & NAME & DESCRIPTION \\
\hline Address & $7-0$ & DATACOM ADDRESS & $\begin{array}{l}\text { Defines the binary address of a remote } \\
\text { receiver on this datacom line. }\end{array}$ \\
\hline \multirow[t]{8}{*}{ Command } & 7 & READY & $\begin{array}{l}\text { Commands power supply to the READY } \\
\text { state when set. }\end{array}$ \\
\hline & 6 & ON & $\begin{array}{l}\text { Commandspower supply to the ON state } \\
\text { when set. }\end{array}$ \\
\hline & 5 & POLARITY & $\begin{array}{l}\text { Commands power supply to polarity A } \\
\text { when set*. }\end{array}$ \\
\hline & 4 & SHUNT OUTPUT & $\begin{array}{l}\text { Commands power supply to place its } \\
\text { shunt voltage on the common shunt } \\
\text { leads when set. }\end{array}$ \\
\hline & 3 & ANNUNCIATOR RESET & $\begin{array}{l}\text { Clears the fault annunciator when } \\
\text { set and no fault present. }\end{array}$ \\
\hline & 2 & Unused & \\
\hline & 1 & Unused & \\
\hline & 0 & SET & $\begin{array}{l}\text { Datacom cycle is a SET cycle when } \\
\text { this bit set. }\end{array}$ \\
\hline
\end{tabular}

MAGNITUDE

15-4 SET POINT

3-0 Unused
Reference input to supply, a 12 bit * binary integer on a scale of $4000_{10}=$ $100 \mathrm{mV}$.
$*$

* Polarity A is such that a bending magnet bends positive particles in the same sense as the AGS ring and that a quadrupole focusses positive particles in the horizontal plane. 
TABLE 1 continued:

Remote to Centra1:

\begin{tabular}{|c|c|c|c|}
\hline FIELD & $\underline{B I T}$ & NAME & DESCRIPTION \\
\hline \multirow[t]{2}{*}{ Address } & $7-4$ & Unused & \\
\hline & $3-0$ & SUB-ADDRESS & $\begin{array}{l}\text { Analog multiplexer address of analog } \\
\text { input. } 0=\text { shunt, } 1=\frac{I}{4} \text { scale reference } \\
2=3 / 4 \text { scale reference. Others un- } \\
\text { defined at present. (The address read } \\
\text { always corresponds with the magnitude } \\
\text { read, even when status bit } 2 \text { is set.) } \\
\text { See READ \& SET CHANNEL. }\end{array}$ \\
\hline \multirow[t]{5}{*}{ Status } & $\begin{array}{l}7 \\
6 \\
5 \\
4\end{array}$ & $\begin{array}{l}\text { READY } \\
\text { ON } \\
\text { POLARITY } \\
\text { SHUNT OUTPUT }\end{array}$ & $\begin{array}{l}\text { The state defined in the corresponding } \\
\text { command bit exists in the power supply } \\
\text { when these bits set. }\end{array}$ \\
\hline & 3 & ANNUNCIATOR & Fault annunciator is set. \\
\hline & 2 & ADC ADDRESS INVALID & $\begin{array}{l}\text { The current magnitude does not correspond } \\
\text { to the latest sub-address sentwhen this } \\
\text { bit set. } * *\end{array}$ \\
\hline & 1 & MODE ERROR & $\begin{array}{l}\text { An illegal mode transition (eg. OFF - ON } \\
\text { no READY) has been requested. }\end{array}$ \\
\hline & 0 & POLARITY ERROR & $\begin{array}{l}\text { An illegal polarity state exists or } \\
\text { transition under load was requested. }\end{array}$ \\
\hline
\end{tabular}

Magnitude $15 \quad$ Unused

15-4 READING Analog to digital converter output, a 12 bit binary integer on a scale of $4000_{10}=100 \mathrm{mV}$.

3-0 Unused

** The analog to digital converter operates continuously and asynchronously with request to the DATACOM. The conversion time (dual slope ADC, 1/60 S integration time) is about $30 \mathrm{~ms}$. Thus the MAGNITUDE received from the remote is the last conversion result and corresponds to the sub-address received. Switching to a new sub-address is synchronized with the start of a new conversion and completion of this conversion clears the ADC INVALID flag bit.

Distribution: Administrative Staff Limited Distribution 